R. J. Hamilton and G. Knight (Mining Research Establishment) found the size distribution of the fine debris $(100 \mu$ to $1 \mu$ in size) produced in the mechanical breakage of coal and rock to be constant in form for each material, but the quantity depends on the breakage process. Stronger materials on shatter produce less total dust than weaker ones, but a greater proportion is dispersed into the atmosphere. H. C. Grimshaw (Safety in Mines Research Establishment) reported similar size distributions from rocks shattered by explosives. Increasing the weight of charge increases the production of fine dust but has little effect on the size distribution. Water infusion reduces the amount of fine dust.

The chairman commented that a number of the papers gave rather unexpected results and confirmed the value of small-scale laboratory work before designing large machines. The constancy of size distributions for very varied breakage processes remains a surprising feature and the results reported, which extend to particles of respirable size, are highly significant for the mining industry.

The chairman of the fourth session, on the action of tools, was Dr. W. Idris Jones, director-general of research in the National Coal Board.

Four papers, all from the Mining Research Establishment, dealt with the action of wedge-type tools on coal. M. J. Dumbleton, M. J. O'Dogherty and $R$. Shepherd described laboratory experiments in 'ploughing' the face off a block of coal, and related the cutting force to the blade angle, depth of cut, strength properties and orientation of the coal specimen. Theoretical aspects of this process were considered by I. Evans, who assumed that the material fails in tension. C. D. Pomeroy gave experimental results for the effect of lateral pressure on the coal specimen on the ploughing forces. The entry of a wedge into specimens with one free face was the subject of a paper by I. Evans and S. A. F. Murrell.

J. H. Brown and C. D. Pomeroy studied friction between coal and metal surfaces.

The chairman commented on the absence of papers on materials other than coal in this session, but considered that the coal industry's problem is probably unique in requiring breakage to handleable size but not smaller. Considerable knowledge exists of metal cutting processes which might be applicable to coal and other brittle materials. There are considerable problems in establishing the relevance of basic measurements to more complicated processes such as ploughing, and further problems in proceeding from the laboratory to underground mining conditions.

The proceedings of the conference will be published in book form.
W. H. WaltoN

\title{
INTERNATIONAL CONGRESS OF APPLIED PSYCHOLOGY
}

$\mathrm{T}$ HE thirteenth International Congress of Applied Psychology was held at the University of Rome during April 9-14. Opening discourses by Prof. Canestrelli, the president, and by Profs. A. Gemelli and $\mathrm{H}$. Pieron gave a conspectus of the scope of the congress and an account of the historical development of applied psychology. More than six hundred participants attended from thirty countries, and some 250 papers were presented. These covered a much wider range of subjects than at previous meetings, a novel feature being the special attention given to medical and, particularly, to legal psychology.

Plenary discussions were devoted to psychological aspects of training industrial managers, medical men, teachers and men of law. The other sessions were occupied, according to this four-fold division, with symposia and individual papers on more general industrial, medical, educational and legal questions.

The sessions on occupational psychology were less concerned with traditional problems of selection, training and environmental conditions of work than with newer questions, such as the specification of criteria for judging the worker's efficiency, the design of tools and machines, the human consequences of automation, industrial mobility, and the vocational rehabilitation of disabled workers. The medical meetings were mainly occupied with personality in physical illness, causes of abnormal behaviour in childhood, effects of hospitalization, analysis of the ideas of normality and abnormality, and sociopsychological aspects of critical physiological phases (for example, pregnancy, ageing) and of psychosomatic medicine. Themes in the educational sessions included the teacher-pupil relationship as a factor in scholastic success, educational and vocational guidance, practical applications of learning theory, 'group dynamics' in the classroom, and the adjustment of school programmes to varying levels of mental development. Finally, the sessions on legal psychology were directed to the problem of evaluating testimony, psychological examination of the accused, the study of criminal gangs, and the readjustment of discharged prisoners.

No participant could attend all the meetings, some of which were held simultaneously. One can therefore do little more than give a personal impression of a rather arbitrary selection of papers widely differing in form and content.

In the industrial section Dr. M. Roche, from Paris, made out a strong case for placing the training of driving instructors on a sound pedagogical basis, so as to ensure that only those who are themselves adequately qualified instructors should be permitted to teach others. Prof. G. Westerlund reported a large-scale statistical and 'inter-disciplinary' study of industrial accidents in Sweden. He suggested that accidents are more likely to ocçur when the worker is new to his job or environment, when his training is inadequate, and when equipment is used to an end for which it was not designed.

Dr. E. V. Gurijanov, of the Academy of Educational Sciences in the U.S.S.R., gave an impressive account of researches at the Laboratory of Labour Psychology, of which he is director. Their aims, he said, were not only to raise the individual's productivity, but also to create the most favourable conditions for the human operator, to improve his vocational skills and aptitudes, and encourage him to adopt 'a creative attitude' towards the solution of industrial problems.

Of more theoretical interest were papers by $\mathrm{Mr}$. P. Bertelson and Mr. R. D. Shepherd, respectively, who studied the response times to stimuli varying in the probability of their appearance. Mr. Bertelson considered the effect of redundance of signals in a sequential task, while Mr. Shepherd was specially 
concerned with common movements made without visual guidance, and he measured the response time in blind positioning reactions made in various emergency conditions.

Two French investigators, C. Benassy-Chauffard and J. Pelnard, analysed the occupational mobility of young workers by the use of methods (developed by Dr. J. M. Faverge) based on the theory of information, whereby the importance of both personal and social factors is assessed. An instructive report on workers' mobility in north Italy was provided by M. Cesa-Bianchi and E. Spaltro. A fresh approach to the study of vocational interests was made by A. Rodger, S. Wiegersma and L. Ancona.

In the medical sessions Prof. L. S. Hearnshaw and H. D. Paul described the present position of psychology in British and German medical schools, respectively. The wide interest in the effects of hospitalization was shown by studies from France, Czechoslovakia, Italy and Great Britain. G. Trentini discussed the immediate effects of hospitalizing cancerous patients. The impact of hospitalization on young children who are chronic invalids or who suffer from organic disability was described by $\mathbf{R}$. Gaddini and Prof. R. W. Pickford. The latter also explained the principles on which successful psychotherapy was based. A first report on the usefulness of training courses by correspondence for patients staying for long periods in British hospitals was given by Dr. H. G. Maule.

Material of a different type was offered by Prof. O. Miyagi, of Tokyo, in the form of a clinical analysis of social pathology in which he contrasted the forms and incidence of mental disorder encountered in Japan with those met in Europe. He also cited characteristic war-time rumours occurring in Japan and compared them with those found by Prof. G. W. Allport among Americans in war-time. Other noteworthy papers included an experimental study by Mr. P. Sainsbury, who claimed, on the basis of electromyographic observations, that individuals tend to preserve a fairly constant level of muscle tension, as Freud suggested, and that gestural movements also have a characteristic level in the individual, such movements as well as conversational gestures increasing in states of anxiety.

An important session on educational psychology was devoted to a symposium on the evaluation of educational achievement ('docimology') presided over by Prof. R. Bonnardel. Other interesting papers were read by Prof. P. E. Vernon on the assessment of higher intellectual qualities, by Mme. TabouretKeller on the elimination of errors in orthography, by Mrs. T. G. Thurstone on the improvement of verbal comprehension, and by Prof. Rosca from Roumania on the effect of alternating activities on proficiency in school-work. He showed by careful experiments that the alternation of activities belonging to different (Pavlovian) signal systems is more efficacious than alternation within the same system.

Far fewer papers were devoted to legal psychology than to the other three themes, but a wide range of subjects revealed growing interest in this field. Apart from the topics already mentioned above, one session was concerned with social influences on delinquency with reports by G. Cohen-Séat, E. Valentini, F. Rabaye and F. M. Raeven on favourable and adverse features in the influence of the cinema. New light on the mind of the homicide was thrown by Dr. A. Paolella's study of projective tests administered to a group of twenty murderers and by Dr. A. Ginsberg's comparable investigation of a mixed group of criminals. A valuable paper on correctional psychology, based on extensive experience at one of the most advanced prisons in Switzerland, was provided by W. Haesler.

It only remains to add that the location of the Congress provided the participants with excellent opportunities for refreshing their memories of the Forum Romanum as well as stimulating their scientific and professional interest in newer developments in applied psychology.
JOHN COHEN

\section{DEVELOPMENT OF THE WEST AFRICAN ENVIRONMENT}

$\mathrm{T}$ HE second Interterritorial Conference of the West African Science Association was held at the University College of Ghana during March 23-29. The theme discussed was "The Development of the West African Environment", and with the aid of a grant from the Rockefeller Foundation, the Association was able to invite a number of scientists noted for their work in this field. The early history of the environment was discussed in relation to the geology, pedology, archæology and palæontology of the region, and its more recent history in relation to plant and animal ecology. Papers were also presented on the effects of recent biotic influences.

Investigations in the south-western Sahara carried out by Prof. Th. Monod, director of the Institut Français d'Afrique Noire, and M. R. Mauny, head of its Department of Prehistory and Archæology, showed how in this region relatively slight climatic changes between ar:d and semi-arid have resulted in marked changes in the flora and fauna. Such changes have also determined the course of human migrations in much of West Africa.

Dr. J. D'Hoore, of the Service Pédologique Interafricain, discussed the many factors involved in the interpretation of the formation of tropical soils, with special reference to the time factor. Further fundamental studies on the processes involved will be necessary before proper understanding of the changes caused in soils by the succession of dry and wet periods is obtained. There is, however, clear evidence from studies of pedogenesis that almost all forest areas of Africa have been subjected to dry periods, and that areas now dry have been under forest. Dr. W. Bruckner and Mr. O. Davies, both of the University College of Ghana, presented the evidence at present available concerning the changes that have taken place in the West African environment as shown by mantle rock and archæological studies in Ghana. Their evidence showed that the succession of pluvial and interpluvial periods in West Africa has followed a course similar to the glacial and interglacial periods in temperate regions. But, as Dr. L. S. B. Leakey, curator of the Coryndon Museum, Nairobi, emphasized, until much more evidence is gathered, reliable correlations between the evidence available from different sciences, and between, for example, East and West Africa, will be very difficult to achieve. 